\title{
Patterns of infection and infectious-related mortality in patients receiving post-transplant high dose cyclophosphamide as graft- versus-host-disease prophylaxis: impact of HLA donor matching
}

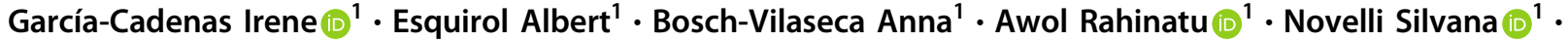 \\ Saavedra Silvana ${ }^{1}$ - Garrido Ana ${ }^{1} \cdot$ López Jordi $^{1} \cdot$ Caballero Ana Carolina ${ }^{1} \cdot$ Granell Miquel $^{1} \cdot$ Moreno Carolina $^{1}$. \\ Briones Javier ${ }^{1} \cdot$ Sierra Jorge $\mathbb{I}^{1} \cdot$ Martino Rodrigo (i) ${ }^{1}$
}

Received: 29 May 2020 / Revised: 6 October 2020 / Accepted: 8 October 2020 / Published online: 26 October 2020

(c) The Author(s), under exclusive licence to Springer Nature Limited 2020

\begin{abstract}
Post-transplant cyclophosphamide (PTCy) has become a promising option after allo-SCT, but infections may be more common than in traditional protocols. We herein report 117 consecutive adults who received PTCy-based alloSCT in our hospital: HaploSCT (34\%), MRD (19\%), and VUD (47\%), respectively. The 18-month incidence of severe bacterial, viral, and IFI was $56 \%, 69 \%$, and $8.7 \%$, without differences between donor type, except for CMV infection and viral hemorrhagic cystitis, which had a higher incidence in the haploSCT cohort (58\% vs. $43 \%$ and $30 \%$ vs. $8 \%$ on day $+90, p<0.05)$. Late infections by conventional respiratory viruses were common in all groups [33/87 (38\%)]. The 2-year survival was $72 \%$ and did not differ by donor type. IRM at day 30, day 100, and 18 months was $1.7 \%, 4.4 \%$, and $12 \%$, without differences by donor type $(p=0.7)$. The primary cause of IRM was bacterial infection $(42 \%)$. Grade $2-4$ acute GvHD was the only independent predictor of IRM. Donor type had no impact on IRM or on survival. In our study, severe infections were common in all donor types using PTCy, with higher rates of early post-engraftment CMV-I and viral HC in haploSCT recipients, although lethal infections were uncommon and similar in all donor types.
\end{abstract}

\section{Introduction}

Infections are a major cause of morbidity and the primary cause of mortality in $35-45 \%$ of deaths after allogeneic hematopoietic stem cell transplantation (alloSCT) [1-6]. Historically, the use of unrelated donors has been associated with an increased risk of severe infectious complications, with more severe infections in non-HLA fully matched transplants [7-10]. Improving immune reconstitution while mitigating graft-versus-host disease (GvHD) has been identified as the key albeit elusive factor for reducing the occurrence of severe opportunistic infections [11].

These authors contributed equally: Sierra Jorge, Martino Rodrigo

$\triangle$ García-Cadenas Irene

Igarciaca@santpau.cat

1 Hematology Department, Hospital de la Santa Creu i Sant Pau, Sant Pau and Jose Carreras Leukemia Research Institutes, Autonomous University of Barcelona, Barcelona, Spain
With the advent of the 20th century, Luzkik et al. [12] pioneered the use of high dose post-transplant cyclophosphamide (PTCy) in the haploidentical SCT (haploSCT) setting, with a surprisingly low incidence of severe forms of both acute and chronic GvHD and similar NRM and survival than alloSCT with other traditional stem cell donor types [13, 14]. At our institution, haploSCT was introduced as the preferred alternative donor source in 2013 using a chemotherapy-only myeloablative conditioning regimen and PTCy plus tacrolimus as GvHD prophylaxis [15]. PTCy was later integrated into HLA-matched related donor (MRD) and HLA-matched or 1-allele mismatched volunteer unrelated donor (VUD) transplant protocols, with positive initial results [16-18], and in 2019 our group published the initial results of incorporatingPTCy as GVHD prophylaxis outside the haploidentical setting [19]. Despite encouraging results, opportunistic infections without severe GVHD were a major concern, being the main cause of death for nonhaploSCT (7 of 19 deaths) and haploSCT (3/4 cases of NRM) recipients in our preliminary studies $[15,19]$.

To further explore this topic, we herein describe the incidence, risk factors, and impact of severe infections on 
long-term outcomes in alloSCT incorporating PTCy for GvHD prophylaxis, with the primary objective of exploring the potential impact of the donor type (haploSCT vs. MDR/ VUD) on these infections.

\section{Patients and methods}

\section{Inclusion criteria and transplant characteristics}

This retrospective cohort includes all consecutive adult patients who received a first alloSCT with PTCy-based GVHD prophylaxis in our institution between June 2013 and January 2020. Patients were treated according to institutional programs in accordance with ethical standards. Written consent for transplant procedures and for the use of medical records for research was obtained from all participants. Data were collected by manual review of the electronic medical records. Main patient characteristics are shown in Table 1.

\section{Conditioning regimen and GvHD prophylaxis}

All patients in the haploSCT group underwent transplantation following our institutional myeloablative conditioning (MAC) Thiotepa-Fludarabine-Bululphan (TBF) protocol, which has been previously described in detail [15]. Similar conditioning regimens were used in the MRD/VUD cohorts, although formally classified as reducedconditioning regimens (RIC) based on low-dose thiotepa combined with the classical Fludarabina-Busulphan or Fludarabine-Melphalan RIC regimens [20-22], as previously reported [19]. In the MAC setting, fludarabine (90 $\mathrm{mg} / \mathrm{m}^{2} \mathrm{IV}$ ) plus fractionated total body irradiation (TBI) at a total dose of 8 to $13.5-\mathrm{Gy}$ or 4 days of busulphan were administered to patients with acute leukemia (AL) or myelodysplastic syndrome (MDS) age $<51$ years [23].

Unmodified hematopoietic progenitor cells, mostly peripheral blood stem cells (PBSC) were infused on Day 0 (target cell dose $5 \times 10^{6} / \mathrm{kg} \mathrm{CD} 34+$ cells). Three patients $(2.6 \%)$ received bone marrow stem cells. PTCy was given days +3 and +4 at a dose of $50 \mathrm{mg} / \mathrm{kg}$ IV once daily, followed by tacrolimus $(0.03 \mathrm{mg} / \mathrm{kg}$ as a $24 \mathrm{~h}$ IV infusion or orally to maintain a target trough serum level of $8 \mathrm{ng} / \mathrm{mL}$, range $5-15 \mathrm{ng} / \mathrm{mL}$ ) starting on day +5 .

Sirolimus was used instead of tacrolimus in case of prior renal failure (loading oral dose of 4 mgr on day +5 followed by $2 \mathrm{mgr}$ daily with dose modifications to maintain a target trough serum level of $7 \mathrm{ng} / \mathrm{mL}$, range $5-12 \mathrm{ng} / \mathrm{mL}$ ). Post-transplant growth factors were not routinely used.
Table 1 Patient characteristics and main transplantation outcomes.

\begin{tabular}{|c|c|c|c|}
\hline & $\begin{array}{l}\text { HaploSCT } \\
(n=40)\end{array}$ & $\begin{array}{l}\text { MRD/VUD/ } \\
\text { MMUD } \\
(n=77)\end{array}$ & $P$ value \\
\hline $\begin{array}{l}\text { Median follow-up for } \\
\text { survivors, range (days) }\end{array}$ & $851(83-2432)$ & $526(42-1488)$ & 0.001 \\
\hline Median age, range & $47(21-71)$ & $54(20-72)$ & 0.15 \\
\hline \multicolumn{4}{|l|}{ Gender } \\
\hline Female & $19(47)$ & $35(45)$ & 0.5 \\
\hline \multicolumn{4}{|l|}{ HLA match } \\
\hline Identical sibling & - & $22(29)$ & 0.001 \\
\hline $\begin{array}{l}\text { 10/10 match } \\
\text { unrelated donor }\end{array}$ & - & $23(30)$ & \\
\hline $\begin{array}{l}9 / 10 \text { mismatch related or } \\
\text { unrelated donor }\end{array}$ & - & $32(41)$ & \\
\hline \multicolumn{4}{|l|}{ Underlying disease } \\
\hline AL/MDS & $28(70)$ & $39(52)$ & 0.2 \\
\hline MPN & $1(2)$ & $10(13)$ & \\
\hline Lymphoid malignancies & $9(23)$ & $20(26)$ & \\
\hline Others & $2(5)$ & $8(11)$ & \\
\hline Disease status at SCT & & & 0.1 \\
\hline CR (first or second) & $29(72)$ & $41(53)$ & \\
\hline Others & $11(28)$ & $36(47)$ & \\
\hline Disease risk index & & & 0.4 \\
\hline High/very high & $15(38)$ & $31(37)$ & \\
\hline Previous SCT & & & 0.8 \\
\hline Yes & $6(15)$ & $10(13)$ & \\
\hline \multicolumn{4}{|l|}{ CMV serology } \\
\hline $\begin{array}{l}\text { Donor positive/Recipient } \\
\text { positive }\end{array}$ & $22(55)$ & $33(43)$ & \\
\hline $\begin{array}{l}\text { Donor negative/Recipient } \\
\text { positive }\end{array}$ & $8(20)$ & $23(30)$ & 0.4 \\
\hline $\begin{array}{l}\text { Donor negative/Recipient } \\
\text { negative }\end{array}$ & $5(12.5)$ & $15(19.5)$ & \\
\hline \multicolumn{4}{|l|}{ Conditioning regimen } \\
\hline $\begin{array}{l}\text { Reduced-intensity } \\
\text { regimen }\end{array}$ & $1(2)$ & $56(73)$ & 0.001 \\
\hline Myeloablative regimen & $39(100)$ & $21(27)$ & \\
\hline Median CD34 + dose $/ \mathrm{kg}$ & $5(1.2-6)$ & $5.5(1.6-8)$ & 0.17 \\
\hline \multicolumn{4}{|l|}{ Acute GvHD } \\
\hline Grades II-IV & $7 / 35(20)$ & $22 / 71(31)$ & 0.3 \\
\hline $\begin{array}{l}\text { Number of patients at } \\
\text { risk for cGvHD at } \\
\text { day }+100\end{array}$ & 30 & 47 & \\
\hline Chronic GvHD & $6(20)$ & 7 (15) & 0.2 \\
\hline
\end{tabular}

MRD HLA-identical matched related donor, VUD HLA-matched volunteer unrelated donor, MMUR 1-allelel mismatched volunteer unrelated donor, $A L$ acute leukemia, $M D S$ myelodysplastic syndrome, $M P N$ myeloproliferative neoplasm, $S C T$ stem cell transplantation, $C R$ complete response, $G v H D$ graft-versus-host disease, $c G v H D$ chronic GvHD. 


\section{Supportive care and anti-infectious prophylaxis}

Patients were nursed in HEPA-filtered rooms during the early post-SCT aplastic period. Most patients received quinolone prophylaxis during neutropenia and/or until the start of broad-spectrum antibiotics. Piperacillin-tazobactam or cefepime alone were used as empirical therapy for febrile neutropenia, unless previous infection with resistant bacteria occurred; in this case, an appropriate antibacterial combination was used. Antiviral prophylaxis consisted of low-dose acyclovir $(400 \mathrm{mg}$ twice a day i.v. or $800 \mathrm{mg}$ orally), which was maintained (in combination with cotrimoxazole) for a minimum of 1 year after SCT or until immunosuppressive therapy was stopped. A mold active antifungal agent (posaconazole, voriconazole, or other systemic antifungal drugs) was used whenever the patient was given high dose steroids for the treatment of GvHD, while fluconazole was used during the pre-engraftment period. Serum galactomannan (2 times per week) was included in the monitoring strategy during this period. Serial blood monitoring using quantitative PCR for cytomegalovirus (CMV) and Epstein-Barr virus (EBV) infection was done 1-2 times a week until day +100 or indefinitely for those with active GvHD, as described elsewhere [24]. Pre-emptive anti-CMV therapy was started when a level of DNAemia of $>1000 \mathrm{IU} / \mathrm{ml}$ was found in one blood sample or two consecutive samples had a level of $>500 \mathrm{IU} / \mathrm{mL}$. Patients with EBV DNAemia of $>1000$ copies $/ \mathrm{mL}$ on at least two consecutive samples were treated with rituximab, as previously described [24].

\section{Transplant and infection-related definitions}

Periods of infectious risk were defined as day 0 to day +30 (pre-engraftment), days +31 to +100 (early post-engraftment) and beyond day +100 (late post-engraftment). Neutrophil engraftment was the first of three consecutive days of ANC $>500$ cells $/ \mathrm{mm}^{3}$ following post-transplant nadir, and platelet engraftment the first of three measurements showing $>20,000$ platelets $/ \mathrm{mm}^{3}$ without platelet transfusion in previous 7 days.

Acute GvHD (aGvHD) and chronic GvHD (cGvHD) were defined per published criteria [25, 26]. Cause of death was determined following the algorithm suggested by Copelan et al. [27].

Infection-related mortality (IRM) was defined as death attributable to a recent severe infection by the primary physician(s) and the coordinator of the study (I.G.) and/or when a lethal infection was identified at autopsy. Any bacterial, viral, or invasive fungal infection (IFI) requiring intravenous treatment, or leading to or prolonging a hospitalization were considered as being severe, as were all $\mathrm{CMV}$ and EBV infections. In case of common skin contaminants, bloodstream infection (BSI) was diagnosed if $\geq 2$ consecutive blood cultures were positive for the same species. Infection data were collected retrospectively until the patient's death or last follow-up, using standardized definitions of severe infections after SCT based on the most recent guidelines (https://www.ebmt.org/working-parties/ infectious-diseases-working-party-idwp). Other severe viral infections considered in this study were: (i) disseminated varicella-zoster virus (VZV) infection; (ii) Human Herpesvirus 6 (HHV-6) encephalitis, diagnosed by positive PCR from cerebrospinal fluid; (iii) Adenovirus (ADV) disease, diagnosed when adenovirus was identified in samples from an affected organ(s) by immunohistochemistry; (iv) pneumonia due to a conventional respiratory virus (CRV); and (v) BK polyomavirus-related hemorrhagic cystitis (BKPV-HC).

\section{Statistical analysis}

The primary objective of the study was to analyze and compare the cumulative incidence (C.I.) of IRM among donor sources (haploSCT vs. MRD/VUD), whereas secondary endpoints were the description of the major types of severe infections. In addition, other conventional posttransplant outcomes were described and compared.

Descriptive statistics were used to show the patients' general characteristics The Kaplan-Meier method was used to estimate actuarial overall survival (OS) and progressionfree survival (PFS). Estimates of neutrophil $\left(>0.5 \times 10^{9} / \mathrm{l}\right)$ and platelet $\left(>20 \times 10^{9} / \mathrm{L}\right)$ recovery, bacterial infections, IFI, severe viral infections, non-relapse mortality (NRM), GVHD, and disease relapse were calculated using cumulative incidence curves, to account for competing risks. Crosstabs and Student's t-test were used to identify baseline characteristics associated with IRM and OS.

Factors with $P$ value $<0.1$ in univariate analysis were entered into a multivariate proportional hazards Cox regression analysis [28]. $P$ values $<0.05$ were considered statistically significant, and the hazard ratios (HRs) and their 95\% confidence intervals (95\% CIs) were calculated. All analyses were performed using SPSS version 18.0 (SPSS Inc, Chicago, IL, USA) or the CMPRSK package in R 2.4.1.

\section{Results}

\section{Patient characteristics}

We included 117 consecutive patients in the study. As shown in Table 1, our cohort contained many high-risk patients. Donors were MRD, fully matched VUD, 1-allelemismatched VUD (MMUD), and haploidentical donors in 
Table 2 Etiologies of the documented infections by time period.

\begin{tabular}{|c|c|c|c|c|}
\hline \multirow[b]{2}{*}{$\begin{array}{l}\text { Only frequencies are } \\
\text { shown in } \\
\text { parenthesis }\end{array}$} & \multicolumn{2}{|c|}{$\begin{array}{l}\text { Pre-engraftment } \\
(\leq 30 \text { days })\end{array}$} & \multicolumn{2}{|c|}{$\begin{array}{l}\text { Intermediate and Late } \\
\text { (>30days) }\end{array}$} \\
\hline & $\begin{array}{l}\text { HaploSCT } \\
(n=40)\end{array}$ & $\begin{array}{l}\text { MRD/ } \\
\text { VUD/ } \\
\text { MMUD } \\
(n=77)\end{array}$ & $\begin{array}{l}\text { HaploSCT } \\
(n=38)\end{array}$ & $\begin{array}{l}\text { MRD/ } \\
\text { VUD/ } \\
\text { MMUD } \\
(n=70)\end{array}$ \\
\hline $\begin{array}{l}\text { Patients with } \\
\geq 1 \text { severe infection }\end{array}$ & $18(45)$ & $31(40)$ & $6(16)$ & $22(31)$ \\
\hline Bacterial infections & 23 & 37 & 10 & 33 \\
\hline Staphylococcus spp & 7 & 17 & 2 & 4 \\
\hline Coagulase negative & 7 & 15 & 2 & 4 \\
\hline Enterococcus spp & 3 & 3 & - & 4 \\
\hline Streptococcus spp & 3 & 5 & 3 & 5 \\
\hline S. pneumoniae & - & - & 2 & 4 \\
\hline $\begin{array}{l}\text { Gram-negative } \\
\text { bacteria }\end{array}$ & 9 & 10 & 4 & 13 \\
\hline C. difficile colitis & 1 & 1 & 1 & 5 \\
\hline Other & - & 1 & - & 2 \\
\hline IFI & 2 & 3 & 1 & 4 \\
\hline IPA & 2 & 2 & 1 & 2 \\
\hline Other & - & 1 & - & 2 \\
\hline Viral infections & 14 & 6 & 49 & 73 \\
\hline \multicolumn{5}{|l|}{ CMV } \\
\hline Reactivation & 7 & 4 & 17 & 29 \\
\hline Disease & - & - & 1 & - \\
\hline EBV & - & - & 3 & - \\
\hline Reactivation & - & - & 3 & - \\
\hline PTLPD & - & - & - & - \\
\hline HSV or VZV & - & - & 4 & 6 \\
\hline HHV-6 encephalitis & 1 & - & - & 2 \\
\hline $\begin{array}{l}\text { Viral haemorrhagic } \\
\text { cystitis }\end{array}$ & 4 & 1 & 8 & 5 \\
\hline $\begin{array}{l}\text { Community- } \\
\text { acquired } \\
\text { respiratory virus }\end{array}$ & 2 & 1 & 14 & 27 \\
\hline Others (highlight) & - & - & 2 & 4 \\
\hline
\end{tabular}

$M R D$ HLA-identical matched related donor, VUD HLA-matched volunteer unrelated donor, MMUR 1-allelel mismatched volunteer unrelated dono, $C M V$ cytomegalovirus, $E B V$ Epstein Barr virus, $P T L P D$ post-transplant lymphoproliferative disorder, HVS Herpes simplex virus, $V Z V$ Varicella-zoster virus, $H H V-6$ Human herpesvirus 6, LRTI low respiratory tract infection.

$22(19 \%), 23(20 \%), 32(27 \%)$, and 40 (34\%) cases, respectively. There were no significant differences in baseline characteristics between the different transplant cohorts. Eighty-six patients (74\%) were CMV seropositive. The median follow-up in survivors was 1056 days (range: 83-2432) in HaploSCT recipients and 526 days (range: 42-1488) in the non-haploidentical cohort, respectively. Thus, follow-up was censored at 18 months (543 days) for all incidence and survival analyses.

\section{Overall outcomes}

Most patients (94\%) achieved neutrophil engraftment, with seven cases developing graft failure. In addition, one patient from each group had an early IRM during aplasia. In the 108 patients with sustained donor engraftment, the median time to neutrophil and platelet recovery was day +20 (range: 12-56) and day +26 (range: $12-171$ ) in haploSCT recipients, while in the non-haplo cohort the median times to neutrophil and platelet recovery were 23 (range: 12-36) and 22 days (range: 10-249), respectively (non-significant differences). The incidence of grade $2-4 \mathrm{aGvHD}$ at day +120 was low in both transplant groups [20.3\% (95\% C.I: 13-28\%) and $29 \%$ (95\% C.I: $19-39 \%$ ), respectively, $p=$ $0.2]$, with a trend for a higher incidence in MMUD transplants [42.6\% (95\% C.I: $32-53$ ) $\mathrm{p}=0.1]$.

Among the 77 evaluable cases, the 1 year C.I. of overall cGvHD was $19.7 \%$ (95\% C.I: $10-27)$ and $11 \%$ (95\% C.I: 2-20) in haplo and non-haplo SCT recipients, while the incidence of moderate-severe forms of cGvHD was 3.8\% and $6 \%$, respectively $(p=0.4)$. No significant differences were found in the 18-month NRM between both groups (13\% vs. $19.8 \%, p=0.5$ ). Again, MMUD transplants had a higher NRM at 18 months [38\% (95\% C.I: $18-48), p=$ 0.05].

The 18-month C.I. of relapse was $18 \%$ (95\% CI $11-29 \%)$ and $29 \%$ (95\% CI 17-41\%) in haploSCT and nonhaploSCT recipients $(p=0.5)$, while the OS was $79.7 \%$ (95\% CI 67-90\%) and 75\% (95\% CI 65-75\%), respectively. The main cause of NRM was an opportunistic infection in both cohorts (12/19 cases of NRM).

\section{Severe infections}

Using microbiological and clinical criteria, 262 severe infections occurred in 98 of 117 patients (84\%), with a median of 2 events/patient (range: 0-7). Major pathogens and their distribution in different post-transplant time periods are summarized in Table 2. Thirty-nine percent were of bacterial, $4 \%$ fungal, and $57 \%$ viral origin. Median time to infection was 14 days for bacterial, 58 days for fungal, and 43 days for viral infection, respectively.

\section{Early severe infections $(<$ day +30$)$}

Overall, 49 patients (42\%) had 60 early post-SCT or preengraftment blood-stream infections (PE-BSI) [median time to the first PE-BSI: 12 days (range: 0-30)]. Coagulasenegative staphylococci were responsible for $37 \%$ of PE-BSI episodes followed by Gram-negative bacteria (GNB) species (32\%) and Streptococcus spp. (13\%). The most represented GNB was Escherichia coli (13\%). Donor type did not influence the rate of PE-BSIs, and the day +30 
Table 3 Univariate and multivariate analysis of the overall survival at 18 months.

\begin{tabular}{|c|c|c|c|c|}
\hline \multirow[t]{2}{*}{ Variables } & \multicolumn{4}{|l|}{ 18-month OS } \\
\hline & $\begin{array}{l}\text { Probability } \\
\text { (95\% C.I.) }\end{array}$ & Univ. $P$ value & Multivariate $\mathrm{P}$ & $\begin{array}{l}\text { HR } \\
\text { (95\% C.I.) }\end{array}$ \\
\hline \multicolumn{5}{|l|}{ Recipient age, in years } \\
\hline$\cdot \leq 40(n=23)$ & $78 \%(70-86)$ & 0.1 & 0.2 & \\
\hline$\cdot>40(n=94)$ & $59 \%(48-70)$ & & & \\
\hline \multicolumn{5}{|l|}{ Disease risk Index } \\
\hline - Low-Intermediate $(n=71)$ & $79.3 \%(69-90)$ & 0.08 & 0.07 & \\
\hline - High-very high $(n=46)$ & $67.4 \%(53-81)$ & & & \\
\hline \multicolumn{5}{|l|}{ CD34 + cell count } \\
\hline$\cdot \geq 5 \times 10 \mathrm{e} 6 / \mathrm{kg}(n=88)$ & $70.3 \%(60-81)$ & 0.1 & 0.09 & \\
\hline$\cdot<5 \times 10 \mathrm{e} 6 / \mathrm{kg}(n=28)$ & $88.2 \%(75-94)$ & & & \\
\hline \multicolumn{5}{|l|}{ 2-4 acute GvHD $^{\mathrm{a}}$} \\
\hline - No $(n=77)$ & $81.6 \%(71-91)$ & 0.06 & 0.02 & $1.6(1.2-2)$ \\
\hline - Yes $(n=29)$ & $69.8 \%(54-85)$ & & & \\
\hline \multicolumn{5}{|l|}{ CMV reactivation ${ }^{a}$} \\
\hline - No $(n=56)$ & $81 \%(69-93)$ & 0.06 & 0.1 & \\
\hline - Yes $(n=56)$ & $68.7 \%(56-79)$ & & & \\
\hline \multicolumn{5}{|l|}{ Invasive fungal infection ${ }^{a}$} \\
\hline - No $(n=107)$ & $78.3 \%(70-84)$ & 0.001 & 0.01 & $3.1(2.5-3.6)$ \\
\hline - Yes $(n=10)$ & $34.3 \%(10-50)$ & & & \\
\hline
\end{tabular}

Other variables tested in the univariate analyses included: recipient and donor sex, conditioning regimen, use of TBI, donor type, development of pre-engraftment bacteremia*, C. difficile colitis*, hemorrhagic cystitis* and moderate-severe cGvHD*. All these variables had a $P$ value $>0.5$ in univariate analysis and are thus not included in the table.

Cum Inc. cumulative incidence, $K-M$ Kaplan-Meier probability, HR Hazard ratio, 95\% C.I. 95\% confidence interval, $G v H D$ Graft versus host disease, $C M V$ cytomegalovirus.

${ }^{a}$ Post-transplant variables were analyzed as time-dependent covariates. incidence of PE-BSI was 45\% (95\%CI: 26-61\%) in haploSCT and $40.5 \%$ (95\%CI: 29-52\%) in non-haploSCT recipients, respectively $(p=0.7)$. In addition, the development of PE-BSI had no impact on survival when analyzed as a time-dependent covariate (see Table 3).

\section{Post-engraftment bacterial infections (beyond day +30 )}

Twenty-eight patients (24\%) had at least one severe bacterial infection beyond day +30 , which occurred at a median of 124 days (range: 34-915) after SCT, with 5 (18\%) of them having more than one episode. The 18-month incidence of post-engraftment bacterial infections was $58.1 \%$ (95\% CI: $43-71)$ in haploSCT recipients and 56\% (95\% CI: 42-70) in the non-haploSCT cohorts $(p=0.9)$.

Fifteen episodes of bacterial infection occurred after day +100 . A GNB was isolated in $40 \%$ of the 43 total episodes of late bacterial infections and six cases were due to Streptococcus pneumoniae. Of note, the rates of these infections did not differ by the presence or absence of grade 2-4aGvHD nor cGvHD (details not shown). Throughout the whole study period, we identified nine $(8.7 \%)$ MDR organisms, mostly MDR-GNB (ESBL producer Enterobacteriaceae in six cases and MDR-P.aeuruginosa in three). Eight patients (7\%) developed $C$. difficile-associated infection, with a median onset of 138 days (range: 6-777) post transplant.

\section{Invasive fungal infections (IFI)}

Three and seven patients $(7.5 \%$ and $9 \%)$ in the haploSCT and non-haploSCT cohorts were diagnosed with an IFI, leading to an overall 100-day and 18-month incidence of 5.3\% (95\% CI: 1-9) and 8.7\% (95\% CI: 3-14), respectively. Most of the cases occurred in the first 100 days after SCT, with a median onset of 58 days (range: 12-609). Invasive aspergillosis (IA) was the most common IFI in both study groups, accounting for $70 \%$ of cases.

\section{CMV and other viral infections}

Fifty-six patients (48\%) developed CMV infection/reactivation (CMV-I) after alloSCT, with a 30-day, 100-day and 18-month incidence of $8.6 \%$ (95\% CI: 3.3-13\%), $46.7 \%$ 


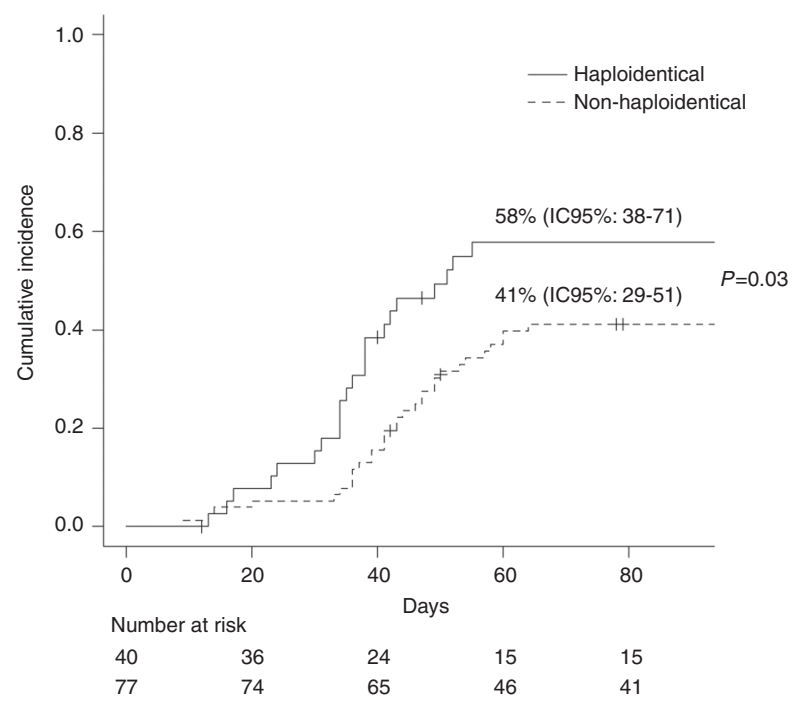

Fig. 1 Cumulative Incidence of CMV infection. Cumulative incidence of CMV infection/reactivation (CMV-I) between days +30 and +90 post transplant in recipients of a HaploSCT vs patients who received transplant from a MRD/VUD/MMUD donor.

(95\% CI: 37-55\%) and 49\% (95\% CI: 38-57\%), respectively. The median onset of CMV-I was 41 days (range: 9-198). CMV disease occurred in only 1 patient Recipients of a HaploSCT had a higher incidence of CMV-I at 18 months than patients who received transplant from a MRD/VUD/MMUD donor [(incidence of 61\% (95\% CI: $41-74 \%)$ vs. $44 \%$ (95\% CI: $31-54 \%)(p=0.03)]$.

As shown in Fig. 1, differences were especially appreciable between days +30 and +90 (45\% vs. $36 \%, p=$ 0.01). When only CMV seropositive recipients were analyzed, the incidence of CMV-I at 90 days was $75.6 \%(95 \%$ CI: $58-92 \%$ ) vs. $53 \%$ (95\% CI: 40-66\%), respectively ( $p=$ 0.009).

The rates of other severe viral infections are detailed in Table 2. Seventeen patients $(14.5 \%)$ had a viral infectionrelated hemorrhagic cystitis $(\mathrm{HC})$ at a median of 47 days after SCT (range: 10-222). Fourteen (82.5\%) were BKPV$\mathrm{HC}$, while adenovirus was implicated in three cases. The rate of viral $\mathrm{HC}$ was higher in haploSCT recipients than in the non-haploSCT groups $(27.5 \%$ vs. $7.8 \%, p=0.01)$. EBV infection was documented in three patients, but without any case of lymphoproliferative disease. HHV-6 encephalitis occurred in three patients $(2.6 \%)$ at a median of 66 days (range: 25-212) post-SCT.

After CMV-I, the most common group of viral infections diagnosed were lower respiratory tract infections (traqueobronchitis with or without pneumonia) by conventional respiratory viruses (CRV), which occurred in 38 patients $(32.5 \%)$. Respiratory syncytial virus $(n=11)$ was the most common CRV. As expected, infections by CRV occurred mostly late after SCT, with a median onset of day +258 (range: 1-1425) and only three cases (7\%) occurring before

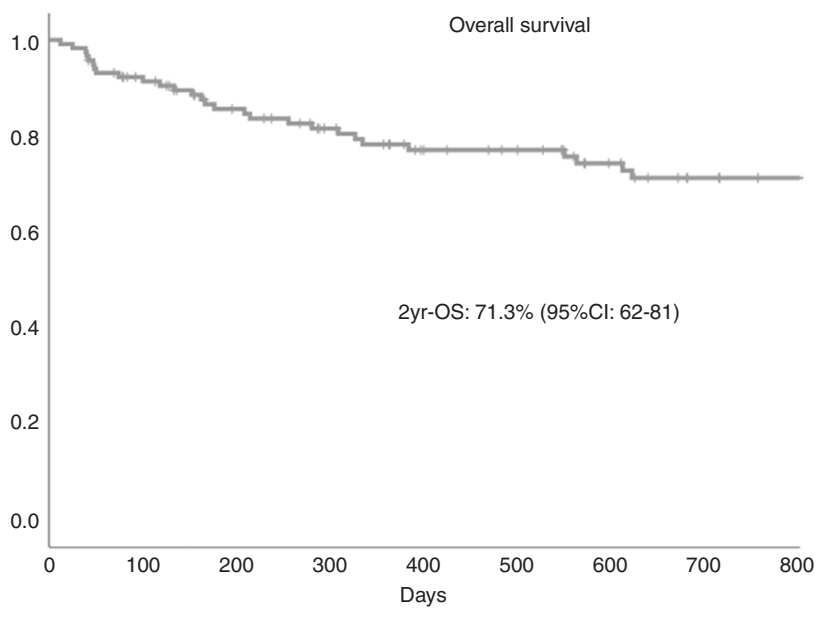

Fig. 2 Overall survival. Overall survival at 2 years.

day +100 . Only two patients died from these infections (pneumonia due to influenza A and SARS-CoV-2 on days +334 and +208 post-SCT, respectively). As shown in Table 2, CRV infections did not differ between haploSCT and non-haploSCT recipients.

\section{Infection-related mortality (IRM) and long-term outcomes}

Infection was the primary cause of death in $36 \%$ of patients who died and a contributing cause in an additional $24 \%$. Median time to IRM was 149 days (range: 12-1266), with $42 \%$ of these deaths occurring in the first 100 days. IRM did not differ between transplant groups. The 18-month incidence of IRM was $7.9 \%$ (95\% CI: 5-13\%) in haploSCT recipients and $13.4 \%$ (95\% CI: 4-19\%) in the nonhaploSCT cohorts, respectively $(p=0.7)$. Bacterial infections were the main cause of IRM $(42 \%)$, followed by viral $(25 \%)$ and IFI (17\%).

At last follow-up, 84 patients were alive (72\%) and 79 of them $(67.5 \%)$ in complete remission with an 18-month OS and PFS of $71.3 \%$ (95\% CI: $62-81 \%$ ) and $67.4 \%$ (95\% CI: 59-75), respectively, and again no differences by donor type ( $p=0.8$; details not shown) (see Fig. 2). In univariate and multivariate analysis only occurrence of grade 2-4 aGvHD increased the risk of IRM ( $p=0.01$, HR 3$)$. With respect to OS (Table 3), grade $2-4$ aGvHD and development of an IFI were significantly associated with higher mortality in multivariate analysis.

\section{Discussion}

In the present analysis, we describe a complete picture of infectious complications in patients receiving an alloSCT 
with PTCy prophylaxis and found that the rates of severe bacterial and fungal infections and the incidence of IRM were similar between the different donors studied. However, this was not the case for several types of postengraftment viral infections, which were more common in haploSCT. Additional interesting findings should be further discussed.

First of all, our results support the lack of significant differences in the overall outcomes using different stem cell donors when high-dose PTCy is used, with low rates of both moderate-to-severe acute and chronic GvHD [16-18, 29]. A possible exception is the trend for higher GvHD and NRM in the MMUD group, which requires further study due to the small patient numbers to date.

Despite the theoretical better infectious profile of PTCy-based strategies compared to T-cell depleted SCT [30-32], we found that infections were a primary or contributing cause of death in around a half of the patients who died in the follow-up period. Of note, IRM was linked to aGvHD, despite the low incidence of severe forms using PTCy.

In terms of bacterial infections, one of the main findings of this study was the similar incidence of PE-BSIs among the different stem cell donors (45\% in haploSCT and $40.5 \%$ in the non-haploSCT cohorts, $p=0.7)$, rates which are comparable to those reported using different GvHD prophylaxis strategies and conditioning regimen intensities [33-37].

Overall, this is a positive observation since PTCy could potentially increase the mucosal barrier injury-linked infections due to more intense and prolonged damage to the gastro-intestinal mucosa combined with a more prolonged duration of neutropenia and monocytopenia, leading to a higher pre-engraftment (before day +30) IRM [38-40]. With respect to post-engraftment infections, there was a low incidence of late bacterial infections (24\% of evaluable cases), probably explained by the low incidence of severe forms of both acute and chronic GvHD. In our report, a total of $8.7 \%$ MDR-bloodstream infections were identified, a lower rate compared to other studies [41-46]. In addition, the 7\% rate of $C$. difficile-associated infection is in the lower range of the previously reported rates of $9-25 \%$ [47-50].

We found an $8.7 \%$ incidence of IFI at 1.5 years, within the current objective of having an incidence $<10 \%$ after alloSCT [51, 52], with the majority of cases occurring after engraftment but before day +100 post transplant. This low incidence of IFI can be explained by the low incidence of GvHD and the reduction in the use of prolonged steroid treatment.

Regarding viral infections, their incidence was high in early post-engraftment phase and more frequent in haploSCT recipients. Both CMV-I and viral HC were especially high in haploSCT recipients between days +30 to +90 post transplant, with incidences of $45 \%$ and $27 \%$, respectively, comparable to other haploSCT studies $[32,40,53,54]$. Beyond day +100 rates of CMV and HC infection were similar between the different stem cell donor groups. Interestingly, we confirmed the low incidence of CMV disease and the lack of EBV-related lymphoproliferative disease, as recently reported by Kanakry et al. [55]. HaploSCT recipients have historically been at increased risk of viral infections because only half of the donor's HLA is expressed by the recipient's antigen presenting cells, potentially leading to delayed HLArestricted immune effector functions if immunodominant HLA loci are missing in the new donor-recipient HLA environment [56].

The lower incidence of infections observed in our study after day $+100[57,58]$ may reflect an effective restoration of antimicrobial immunity during the post transplant period, favored in part by the low rate of both acute and chronic GvHD.

Prior studies have reported an incidence of IRM of $9 \%$ to $20 \%$ in patients receiving PTCy-based alloSCT platforms $[30,32,40]$, although most studies have focused on haploSCT since this has been the most common setting for the use of PTCy. Our finding of a 9\% IRM at 18 months, without differences between haploSCT and MRS/VUD/ MMUD is thus promising.

The current study shares the limitations inherent to all retrospective analyses of complex clinical scenarios, including potential selection bias, as we cannot exclude the possibility that some non-severe infections were not captured because of incomplete reporting. However, all patients were followed at the same institution; therefore it is unlikely that clinically-relevant infectious complications were systematically missed; moreover, the diagnostic procedures and prophylactic measures were similar for all patients, thus contributing to the homogeneity in the diagnosis of the infectious events. In addition, as far as we know there are no previous studies providing detailed information on infectious morbidity and mortality after PTCy over an extended period of time and comparing the results between different stem cell donors.

In conclusion, our analysis found that severe infections were the main cause of NRM after alloSCT with PTCy, although their incidence was low in both donor groups. We did not observe remarkable differences in rates, microorganisms involved or diagnosis period of infection except in case of CMV and viral $\mathrm{HC}$ which were more frequently diagnosed early post-engraftment in the haploidentical cohort. Our data supports yet another promising role of using PTCy as GvHD prophylaxis, although efforts toward reducing the rates of CMV-I and viral $\mathrm{HC}$, especially in haploSCT recipients, are clearly needed. 


\section{Compliance with ethical standards}

Conflict of interest The authors declare that they have no conflict of interest.

Publisher's note Springer Nature remains neutral with regard to jurisdictional claims in published maps and institutional affiliations.

\section{References}

1. Kim SH, Kee SY, Lee DG, Choi SM, Park SH, Kwon JC, et al. Infectious complications following allogeneic stem cell transplantation: reduced-intensity vs myeloablative conditioning regimens. Transpl Infect Dis. 2013;15:49-59.

2. Yoo JH, Lee DG, Choi SM, Choi JH, Park YH, Kim YJ, et al. Infectious complications and outcomes after allogeneic hematopoietic stem cell transplantation in Korea. Bone Marrow Transpl. 2004;34:497-504.

3. Ninin E, Milpied N, Moreau P, Andre-Richet B, Morineau N, Mahe B, et al. Longitudinal study of bacterial, viral, and fungal infections in adult recipients of bone marrow transplants. Clin Infect Dis. 2001;33:41-47.

4. Mitchell AE, Derrington P, Turner P, Hunt LP, Oakhill A, Marks DI. Gram-negative bacteraemia (GNB) after 428 unrelated donor bone marrow transplants (UD-BMT): risk factors, prophylaxis, therapy and outcome. Bone Marrow Transpl. 2004;33:303-10.

5. Junghanss C, Marr KA. Infectious risks and outcomes after stem cell transplantation: are nonmyeloablative transplants changing the picture? Curr Opin Infect Dis. 2002;15:347-53.

6. Leather HL, Wingard JR. Infections following hematopoietic stem cell transplantation. Infect Dis Clin North Am. 2001;15:483-520.

7. van Kraaij MG, Verdonck LF, Rozenberg-Arska M, Dekker AW. Early infections in adults undergoing matched related and matched unrelated/mismatched donor stem cell transplantation: a comparison of incidence. Bone Marrow Transpl. 2002;30:303-9.

8. Williamson EC, Millar MR, Steward CG, Cornish JM, Foot AB, Oakhill $\mathrm{A}$, et al. Infections in adults undergoing unrelated donor bone marrow transplantation. Br J Haematol. 1999;104:560-8.

9. Small TN, Papadopoulos EB, Boulad F, Black P, CastroMalaspina $\mathrm{H}$, Childs $\mathrm{BH}$, et al. Comparison of immune reconstitution after unrelated and related T-cell-depleted bone marrow transplantation: effect of patient age and donor leukocyte infusions. Blood. 1999;93:467-80.

10. Bjorklund A, Aschan J, Labopin M, Remberger M, Ringden O, Winiarski J, et al. Risk factors for fatal infectious complications developing late after allogeneic stem cell transplantation. Bone Marrow Transplant. 2007;40:1055-62. Epub 2007 Sep 24

11. Atilla E, Atilla PA, Bozdağ SC, Demirer T. A review of infectious complications after haploidentical hematopoietic stem cell transplantations. Infection. 2017;45:403-11.

12. Luznik L, O'Donnell PV, Symons HJ, Chen AR, Leffell MS, Zahurak M, et al. HLA-haploidentical bone marrow transplantation for hematologic malignancies using nonmyeloablative conditioning and high-dose, posttransplantation cyclophosphamide. Biol Blood Marrow Transpl. 2008;14:641-50.

13. Bashey A, Zhang X, Jackson K, Brown S, Ridgeway M, Solh M, et al. Comparison of outcomes of hematopoietic cell transplants from T-replete haploidentical donors using post-transplantation cyclophosphamide with 10 of 10 HLA-A, -B, -C, -DRB1, and -DQB1 allelematched unrelated donors and hla-identical sibling donors: a multivariable analysis including disease risk index. Biol Blood Marrow Transpl. 2016;22:125-33.
14. Sun Y, Beohou E, Labopin M, Volin L, Milpied N, Yakoub-Agha I, et al. Unmanipulated haploidentical versus matched unrelated donor allogeneic stem cell transplantation in adult patients with acute myelogenous leukemia in first remission: a retrospective pair-matched comparative study of the Beijing approach with the EBMT data base. Haematologica. 2016;101:e352-4.

15. Esquirol A, Querol S, Garcia-Cadenas I, Novelli S, Garrido A, Saavedra S, et al. When an HLA identical donor is not available in adults with hematological neoplasms: single-center comparison of single-unit cord blood transplantation and haploidentical-related PBSC transplantation with PTCy using a standardized conditioning platform (thiotepa-busulfan-fludarabine). Ann Hematol. 2020 Jan;99:157-65.

16. Ruggeri A, Labopin M, Bacigalupo A, Afanasyev B, Cornelissen JJ, Elmaagacli A, et al. Posttransplant cyclophosphamide for GVHD prophylaxis in HLA matched sibling or matched-unrelated donor transplant for patients with acute leukemia, on behalf of ALWP-EBMT. J Hematol Oncol. 2018;11:40.

17. Shah MV, Saliba RM, Rondon G, Chen J, Soebbing D, Rus I, et al. Pilot study using post-transplant cyclophosphamide (PTCy), tacrolimus and mycophenolate GVHD prophylaxis for olderpatientsreceiving 10/10 HLA-matched unrelated donor hematopoietic stem cell transplantation. Bone Marrow Transpl. 2019;54:601-6.

18. Prem S, Atenafu EG, Al-Shaibani Z, Loach D, Law A, Lam W, et al. Low rates of acute and chronic GVHD with ATG and PTCy in matched and mismatched unrelated donor peripheral bloodstem cell transplants. Eur J Haematol. 2019;102:486-93.

19. García-Cadenas I, Awol R, Esquirol A, Saavedra S, BoschVilaseca A, Novelli $S$, et al. Incorporating posttransplant cyclophosphamide-based prophylaxis as standard-of-care outside the haploidentical setting: challenges and review of the literature. Bone Marrow Transpl. 2020;55:1041-9.

20. Martino R, Iacobelli S, Brand R, Jansen T, van Biezen A, Finke J, et al. Retrospective comparison of reduced-intensity conditioning and conventional high-dose conditioning for allogeneic hematopoietic stem cell transplantation using HLA-identical sibling donors in myelodysplasticsyndromes. Myelodysplastic Syndrome subcommittee of the Chronic Leukemia Working Party of the European Blood and Marrow Transplantation Group. Blood. 2006;108:836-46.

21. Parody R, Lopez-Corral L, Godino OL, Cadenas IG, Martinez AP, Vazquez L, et al. GVHD prophylaxis with sirolimus-tacrolimus may overcome the deleterious effect on survival of HLA mismatch after reduced-intensity conditioning alloSCT. Bone Marrow Transpl. 2015;50:121-6.

22. Piñana JL, Valcárcel D, Fernández-Avilés F, Martino R, Rovira M, Barba P, et al. MTX or mycophenolatemofetil with CsA as GVHD prophylaxis after reduced-intensity conditioning PBSCT from HLAidentical siblings. Bone Marrow Transpl. 2010;45:1449-56.

23. Kanakry CG, O’Donnell PV, Furlong T, de Lima MJ, Wei W, Medeot M, et al. Multi-institutional study of post-transplantation cyclophosphamide as single-agent graft-versus-host disease prophylaxis after allogeneic bone marrow transplantation using myeloablativebusulfan and fludarabine conditioning. J Clin Oncol. 2014;32:3497-505.

24. Piñana JL, Martino R, Barba P, Margall N, Roig MC, Valcárcel D, et al. Cytomegalovirus infection and disease after reduced intensity conditioning allogeneic stem cell transplantation: singlecentre experience. Bone Marrow Transpl. 2010;45:534-42.

25. Przepiorka D, Weisdorf D, Martin P, Klingemann HG, Beatty P, Hows J, et al. Consensus conference on acute GVHD grading. Bone Marrow Transpl Bone Marrow Transpl. 1995;15:825-8.

26. Lee StephanieJ, Wolff D, Kitko C, Koreth J, Inamoto Y, et al. Measuring therapeutic response in chronic graft-versus-host 
disease. national institutes of health consensus development project on criteria for clinical trials in chronic graft-versus-host disease: IV. the 2014 response Criteria Working Group. Biol Blood Marrow Transpl. 2015;21:984-99.

27. Copelan E, Casper JT, Carter SL, van Burik JAH, Hurd D, Mendizabal AM, et al. A scheme for defining cause of death and its application in the $\mathrm{T}$ cell depletion trial. Biol Blood Marrow Transpl. 2007;13:1469-76.

28. Fine JP, Gray RJ. A proportional hazards model for the subdistribution of acompeting risk. $\mathrm{J}$ Am Stat Assoc. 1999;94:496-509.

29. Ruggeri A, Labopin M, Bacigalupo A, Afanasyev B, Cornelissen JJ, Elmaagacli A, et al. Post-transplant cyclophosphamide for graft-versus-host disease prophylaxis in HLA matched sibling or matched unrelated donor transplant for patients with acute leukemia, on behalf of ALWP-EBMT. A J Hematol Oncol. 2018;11:40.

30. Fayard A, Daguenet E, Blaise D, Chevallier P, Labussière H, Berceanu A, et al. Evaluation of infectious complications after haploidentical hematopoietic stem cell transplantation with posttransplant cyclophosphamide following reduced-intensity and myeloablative conditioning: a study on behalf of the Francophone Society of Stem Cell Transplantation and Cellular Therapy (SFGM-TC). Bone Marrow Transpl. 2019;54:1586-94.

31. Mohty R, Brissot E, Battipaglia G, Ruggeri A, Dulery R, et al. Infectious complications after post-transplantation cyclophosphamide and anti-thymocyte globulin-based haploidentical stem cell transplantation. Br J Haematol. 2019;187:e64-e68.

32. Crocchiolo R, Bramanti S, Vai A, Sarina B, Mineri R, Casari E, et al. Infections after T-replete haploidentical transplantation and high-dose cyclophosphamide as graft-versus-host disease prophylaxis. Transpl Infect Dis. 2015;17:242-9.

33. Dandoy CE, Kim S, Chen M, Ahn KW, Ardura MI, Brown V, et al. Incidence, risk factors, and outcomes of patients who develop mucosal barrier injury-laboratory confirmed bloodstream infections in the first 100 days after allogeneic hematopoietic stem cell transplant. JAMA Netw Open. 2020;3:e1918668. 3

34. Dandoy CE, Ardura MI, Papanicolaou GA, Auletta JJ. Bacterial bloodstream infections in the allogeneic hematopoietic cell transplant patient: new considerations for a persistent nemesis. Bone Marrow Transpl. 2017;52:1091-106.

35. Mikulska M, Raiola AM, Galaverna F, Balletto E, Borghesi ML, Varaldo R, et al. Preengraftment bloodstream infections after allogeneic hematopoietic cell transplantation: impact of $\mathrm{T}$ cellreplete transplantation from a haploidentical donor. Biol Blood Marrow Transpl. 2018;24:109-18.

36. Martino R, Bautista G, Parody R, García I, Esquirol A, Rovira M, et al. Severe infections after single umbilical cord blood transplantation in adults with or without the co-infusion of CD34+ cells from a third-party donor: results of a multicenter study from the Grupo Español de Trasplante Hematopoyético (GETH). Transpl Infect Dis. 2015;17:221-33.

37. Parody R, Martino R, Rovira M, Vazquez L, Vázquez MJ, de la Cámara $\mathrm{R}$, et al. Severe infections after unrelated donor allogeneic hematopoietic stem cell transplantation in adults: comparison of cord blood transplantation with peripheral blood and bone marrow transplantation. Biol Blood Marrow Transpl. 2006;12:734-48.

38. Almyroudis NG, Fuller A, Jakubowski A, Sepkowitz K, Jaffe D, Small T, et al. Pre- and post-engraftment bloodstream infection rates and associated mortality in allogeneic hematopoietic stem cell transplant recipients. Transpl Infect Dis. 2005;7:11-7.

39. Chang J, Hsiao M, Blodget E, Akhtari MJ. Increased risk of 100day and 1-year infection-related mortality and complications in haploidentical stem cell transplantation. Blood Med. 2019; 10:135-43. 15
40. Oltolini C, Greco R, Galli L, Clerici D, Lorentino F, Xue E, et al. Infections after allogenic transplant with post-transplant cyclophosphamide: impact of donor HLA matching. Biol Blood Marrow Transpl. 2020;S1083-8791:30045-8. 28

41. Patriarca F, Cigana C, Massimo D, Lazzarotto D, Geromin A, Isola $\mathrm{M}$, et al. Risk factors and outcomes of infections by multidrug-resistant gram-negative bacteria in patients undergoing hematopoietic stem cell transplantation. Biol Blood Marrow Transpl. 2017;23:333-9.

42. Puerta-Alcalde $\mathrm{P}$, Cardozo C, Marco F, Suárez-Lledó M, Moreno E, Morata L, et al. Changing epidemiology of bloodstream infection in a 25-years hematopoietic stem cell transplant program: current challenges and pitfalls on empiric antibiotic treatment impacting outcomes. Bone Marrow Transpl. 2020;55:603-12.

43. Bilinski J, Robak K, Peric Z, Marchel H, Karakulska-Prystupiuk E, Halaburda K. Impact of gut colonization by antibiotic-resistant bacteria on the outcomes of allogeneic hematopoietic stem cell transplantation: a retrospective, single-center study. Biol Blood Marrow Transpl. 2016;22:1087-93.

44. Mikulska M, Bono V, Raiola A, Bruno B, Gualandi F, Occhini D, et al. Blood stream infections in allogeneic hematopoietic stem cell transplant recipients: reemergence of gram-negative rods and increasing antibiotic resistance. Biol Blood Marrow Transpl. 2009;15:47-53.

45. Liu C, Frank DN, Horch M, Chau S, Ir D, Horch EA, et al. Associations between acute gastrointestinal GvHD and the baseline gut microbiota of allogeneic hematopoietic stem cell transplant recipients and donors. Bone Marrow Transpl. 2017;52:1643-50.

46. Köhler N, Zeiser R. Intestinal microbiota influence immune tolerance post allogeneic hematopoietic cell transplantation and intestinal GVHD. Front Immunol. 2019;9:3179. 17.

47. Willems L, Porcher R, Lafaurie M, Casin I, Robin M, Xhaard A, et al. Clostridium difficile infection after allogeneic hematopoietic stem cell transplantation: incidence, risk factors, and outcome. Biol Blood Marrow Transpl. 2012;18:1295-301.

48. Alonso CD, Treadway SB, Hanna DB, Huff CA, Neofytos D, Carroll KC, et al. Epidemiology and outcomes of Clostridium difficile infections in hematopoietic stem cell transplant recipients. Clin Infect Dis. 2012;54:1053-63.

49. Santiago M, Eysenbach L, Allegretti J, Aroniadis O, Brandt LJ, Fischer M, et al. Microbiome predictors of dysbiosis and VRE decolonization in patients with recurrent $C$. difficile infections in a multi-center retrospective study. Microbiol. 2019;5:1-18. 17

50. Alonso $\mathrm{CD}$, Marr KA. Clostridium difficile infection among hematopoietic stem cell transplant recipients: beyond colitis. Curr Opin Infect Dis. 2013;26:326-31.

51. Kontoyiannis DP, Marr KA, Park BJ, Alexander BD, Anaissie EJ, Walsh TJ, et al. Prospective surveillance for invasive fungal infections in hematopoietic stem cell transplant recipients, 2001-6: overview of the Transplant-Associated Infection Surveillance Network (TRANSNET) Database. Clin Infect Dis. 2010;50:1091-100. 15

52. Liu YC, Chien SH, Fan NW, Hu MH, Gau JP, Liu CJ, et al. Incidence and risk factors of probable and proven invasive fungal infection in adult patients receiving allogeneic hematopoietic stem cell transplantation. J Microbiol Immunol Infect. 2016;49:567-74.

53. Ruggeri A, Roth-Guepin G, Battipaglia G, Mamez AC, Malard F, Gomez A, et al. Incidence and risk factors for hemorrhagic cystitis in unmanipulated haploidentical transplant recipients. Transpl Infect Dis. 2015;17:822-30.

54. Copelan OR, Sanikommu SR, Trivedi JS, Butler C, Ai J, Ragon $\mathrm{BK}$, et al. Higher incidence of hemorrhagic cystitis following haploidentical related donor transplantation compared with 
matched related donor transplantation. Biol Blood Marrow Transpl. 2019;25:785-90.

55. Kanakry JA, Kasamon YL, Bolaños-Meade J, Borrello IM, Brodsky RA, Fuchs EJ, et al. Absence of post-transplantation lymphoproliferative disorder after allogeneic blood or marrow transplantation using post-transplantation cyclophosphamide as graft-versus-host disease prophylaxis. Biol Blood Marrow Transpl. 2013;19:1514-7.

56. Chang YJ, Zhao XY, Huang XJ. Immune reconstitution after haploidentical hematopoietic stem cell transplantation. Biol Blood Marrow Transpl. 2014;20:440.
57. Marinelli T, Wee LYA, Rowe E, Chhetri R, Friel O, Higgins G, et al. Respiratory viruses cause late morbidity in recipients of hematopoietic stem cell transplantation. Biol Blood Marrow Transpl. 2020;26:782-8.

58. Piñana JL, Gómez MD, Pérez A, Madrid S, Balaguer-Roselló A, Giménez E, et al. Community-acquired respiratory virus lower respiratory tract disease in allogeneic stem cell transplantation recipient: risk factors and mortality from pulmonary virus-bacterial mixed infections. Transpl Infect Dis. 2018;20: e12926. 